\title{
EFFECT OF THE SUB-COOLING ON A BUBBLE DyNAMiCs in PoOl BoILing
}

\author{
Mirela Alispahić \& Šefko Šikalo
}
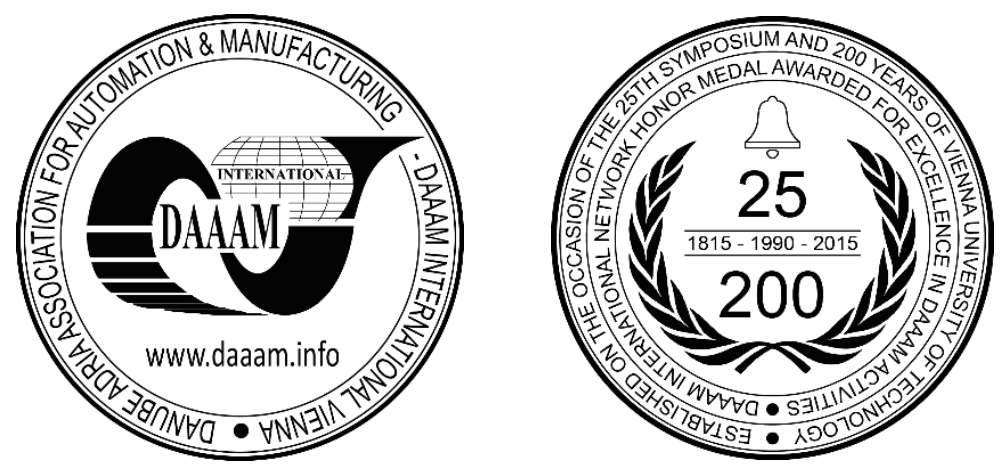

This Publication has to be referred as: Alispahic, M[irela] \& Sikalo, S[efko] (2018). Effect of the Subcooling on a Bubble Dynamics in Pool Boiling, Proceedings of the 29th DAAAM International Symposium, pp.0731-0739, B. Katalinic (Ed.), Published by DAAAM International, ISBN 978-3-902734-20-4, ISSN 1726-9679, Vienna, Austria DOI: $10.2507 / 29$ th.daaam.proceedings.106

\begin{abstract}
Results of experimental study of sub-cooled pool boiling of distilled water on copper and brass surfaces are presented in this paper. Visualization of the boiling process is performed in conditions of high sub-cooling $\left(\Delta T_{\text {sub }}=40 \mathrm{~K}\right)$ in order to get new data for bubble formation, increase and its departure from the solid surface at different degree of surface superheat $\left(\Delta T_{\text {sat }}=0 \div 10 \mathrm{~K}\right)$. Pool boiling of water, presented in this paper, is characterized by high surface density of bubbles. The parameters related to bubble growth characteristics (bubble formation and base diameter, time of the bubble growth and contact angle) and bubble departure characteristics (diameter and frequency) are qualitatively and quantitatively presented in terms of the degree of superheat. The departure diameters of this experiment are compared with that calculated using correlations available in the literature.
\end{abstract}

Keywords: sub-cooled pool boiling; base bubble diameter; departure bubble diameter; bubble contact angle; bubble growth time

\section{Introduction}

Nucleate boiling has been a subject of study for several decades, because of its very efficient heat transfer mechanism encountered in many industrial applications (e.g. steam generators, heat exchangers, cooling equipment, etc.). High heat transfer coefficients in nucleate boiling are connected with bubble activity on the heated surface. Therefore, almost all proposed correlations to predict heat transfer coefficients are related to bubble dynamics. An excellent review of departure diameter and frequency was given by [1]. Fritz [2] correlated the bubble departure diameter $D_{\mathrm{d}}$ by balancing buoyancy force with surface tension force. The empirical correlation for bubble departure diameter involving contact angle is given as:

$$
D_{d}=0.0208 \theta \sqrt{\frac{\sigma}{g\left(\rho_{l}-\rho_{v}\right)}}
$$

where $\theta$ is the contact angle measured in degrees (35 for mixtures and 45 for water). It is important to note that the proposed correlation is based on measurements carried out with air bubbles but not in the process of boiling. 
Latter, Cole [3] has modified Fritz [2] correlation eliminating the contact angle term and involving the heat flux trough the surface temperature which appears in Jacob number $\left(\mathrm{Ja}=\rho_{l} c_{p, l} \Delta T / \rho_{v} h_{f g}\right)$, as:

$$
D_{d}=0.04 \mathrm{Ja} \sqrt{\frac{\sigma}{g\left(\rho_{l}-\rho_{v}\right)}}
$$

The Cole [3] correlation has a reasonable prediction of diameter only for pure liquids and mixtures for saturated boiling. Phan et al. [4] measured the bubble departure diameter of water on sample surfaces having different contact angles and found that evolution trend of departure diameter with contact angle disagrees with that suggested by Fritz [2]. Phan et al. [4] proposed the following correlation:

$$
D_{d}=0.626977 \times f(\theta) \sqrt{\frac{\sigma}{g\left(\rho_{l}-\rho_{v}\right)}}
$$

where $f(\theta)=\left(2+3 \cos \theta-\cos ^{3} \theta\right) / 4$ is energy factor considering the wetting effects. They performed experiments to study the effects of the surface wettability on nucleation mechanism and sub-cooled boiling heat transfer. It is important to note that their model is valid only for isolated bubbles detaching from horizontal surface and do not take into account the effects of surface superheat.

The present work aims to improve the understanding of the effect of high sub-cooling on bubble growth and departure characteristics in case of high bubble surface densities. There are not sufficient data for the values of these parameters in sub-cooled boiling regime, because bubble dynamics is mostly studied for saturated boiling conditions. Also, the above-mentioned characteristics have not been investigated in detail for randomly rough surfaces. Recently, McHale and Garimella [5] experimentally investigated saturated pool boiling characteristics of FC-77 on the practical surfaces (aluminium block with the smooth and the rough surface finish). The pool boiling observed is characterized by high bubble densities and numerous interactions between bubbles. They found that bubble departure diameter and the active nucleation site density are shown to increase with wall superheat but the surface roughness is also shown to have influence. Demiray and Kim [6] experimentally investigated bubble growth and departure characteristics for bubbles nucleating from a single site for sub-cooled FC-72 $\left(52^{\circ} \mathrm{C}\right.$ and $41^{\circ} \mathrm{C}$ for low and high sub-cooling, respectively) with wall temperature fixed at $76^{\circ} \mathrm{C}$. They found that the bubbles are significantly smaller in high sub-cooling case than those in low sub-cooling case because of thinning superheated liquid layer in the high sub-cooled case.

\section{Experimental setup}

A schematic of the set-up used in the experiment is shown in Fig. 1.

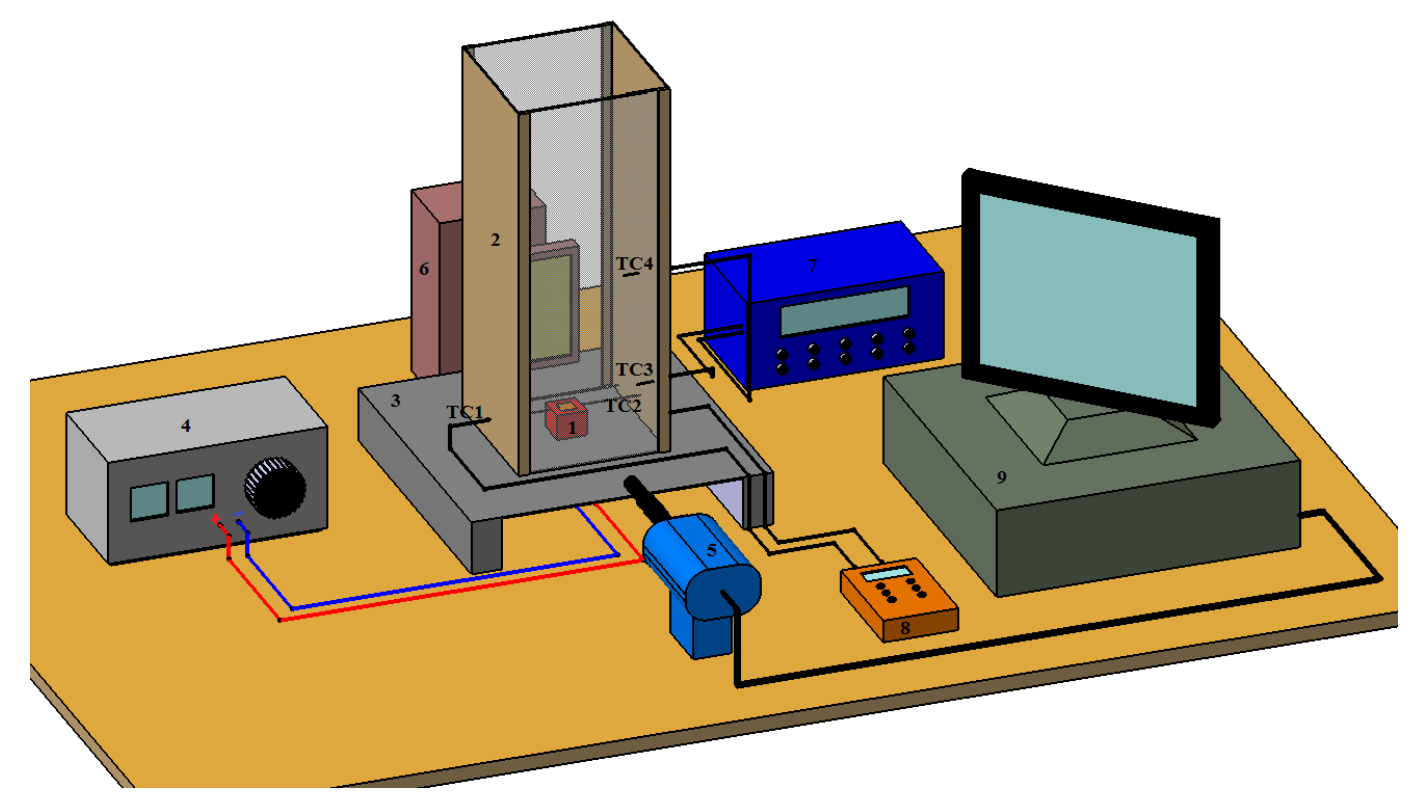

Fig. 1. Experimental setup: 1-test block; 2-boiling vessel; 3-metal support; 4-DC-power supply; 5-HS camera; 6-LED backlight; 7,8-DAQ; 9-PC; TC-thermocouple. 
The boiling vessel is made of steel on two sides while the front and back sides were made of glass to allow the visualization of the boiling process. The vessel dimensions are $150 \times 150 \times 250$ in $\mathrm{mm}$ with open top in order to maintain atmospheric boiling conditions. The test block is maintained horizontally and fixed inside the boiling vessel. The lateral sides of the test block are thermally insulated with silicon paste, to enable control of heat transfer area to upper horizontal side of the block and to avoid parasite nucleation sites.

The heat transfer area is $20 \times 20 \mathrm{~mm}$ bare top surface of the test block. A DC power supply $(0-30 \mathrm{~V}, 0-15 \mathrm{~A})$ is connected to the $5.2 \mathrm{~mm}$ diameter cartridge heater which is inserted at the bottom of the test block. The test block and the vessel is sealed with silicon paste to prevent a leakage from the vessel. Four K-type thermocouples with an accuracy of $\pm 0.3^{\circ} \mathrm{C}$ are connected to the data acquisition (Agilent $34970 \mathrm{~A}$ ).

The thermocouples TC1 and TC2 are inserted to the test block close to the boiling surface (1.5 mm under the surface). Thermal paste is used to reduce thermal contact resistance between thermocouples and test block. The thermocouples TC3 and TC4 are used to measure the bulk liquid temperature; TC3 is positioned next to the boiling surface and TC4 is located $45 \mathrm{~mm}$ above the test surface. The test surface temperatures are taken as averaged values of thermocouples TC1 and TC2.

In addition, the heat flux is measured using a thin flux meter (thickness of the sensor is $0.18 \mathrm{~mm}$ with a thermal resistance of $0.002{ }^{\circ} \mathrm{C} \cdot \mathrm{m}^{2} / \mathrm{W}$ and a sensitivity of $0.981 \mu \mathrm{V} /\left(\mathrm{W} / \mathrm{m}^{2}\right)$ ) attached to heated surface in ambient air and values are compared with heat flux calculated from applied power input to the heater.

Two test surfaces with almost same roughness (copper and brass, prepared by mechanical polishing, $R_{\mathrm{a}}=0.55 \mu \mathrm{m}$ and $R_{\mathrm{a}}=0.54 \mu \mathrm{m}$, respectively), are used. The distilled water was used as test liquid.

A high-resolution camera (pco. 1200s) is used to visualise the boiling process. For the experiments the recording speed of the camera has been set at $520 \mathrm{fps}$ and a spatial resolution of $1280 \times 1024$ pixels. The image calibration is carried out using the known dimensions of the etalon plates with chosen magnification of the imaging Navitar lens (adopted spatial resolution is $16 \mu \mathrm{m}$ per pixel). The camera is set up laterally to the boiling vessel in order to capture the side view of the phenomenon. A backlighting technique with a flat LED light and a glass diffuser was used.

\subsection{Experimental procedure}

The test surface and the boiling vessel are cleaned afterward the distilled water was poured into the vessel. The pool boiling tests start by degassing the distilled water for about 1 hour to minimize the possibility of presence of dissolved gases in working fluid. An auxiliary heater $(1200 \mathrm{~W})$ is used to heat the water to the saturation temperature. Then, the system is left to cool down to the required bulk temperature.

The test surface temperature is controlled by changing the supply voltage and current of the heater. The applied power input is increased stepwise in order to obtain bubble nucleation, growth departure characteristics for each test surface based on a high speed visualisation. The camera is started after the steady-state conditions are achieved (approximately 8 minutes after each power input increase).

The high speed visualization leads to a large number of images to treat in order to obtain data of interest with the adopted frame-by-frame post-processing image procedure. The minimum of five consecutive bubbles from the individual nucleation sites on the surface, identified in the extracted images, are observed from initiation of the growth (the time when the bubble is first time spotted in the image frame) to the time they disappeared from the image frame.

\section{Experimental results}

In order to quantify the wettability of the test surfaces, the equilibrium static contact angle, $\theta_{0}$, is measured at $20^{\circ} \mathrm{C} \pm 2{ }^{\circ} \mathrm{C}$ in ambient air by using the sessile drop technique (Table 1). Hysteresis (i.e. the difference between apparent advancing and receding angles) is also obtained for the test surfaces and shown in Table 1.

\begin{tabular}{|c|c|c|}
\hline Test surface & $\theta_{\mathrm{o}}$ & $\theta_{\mathrm{a}}-\theta_{\mathrm{r}}$ \\
\hline Copper & 56 & 87 \\
\hline Brass & 60 & 90 \\
\hline
\end{tabular}

Table 1. The contact angles for distilled water.

All data for boiling process are obtained with the degree of sub-cooling fixed at $\Delta T_{\text {sub }}=40 \mathrm{~K}$ and ambient pressure $p_{\text {amb }}=0.950$ bar. Figure 2 illustrates photographs of the bubble forming on brass surface at low input power, with corresponding degree of wall superheat of $3 \mathrm{~K}$. Formed bubbles stay attached to the surface (a steady-state vapour bubbles) for long period of time in a pool of sub-cooled water. With the appearance of the bubbles the superheated stream which is emerged from bubbles tops penetrates into the colder bulk water in the direction of the gravity. 


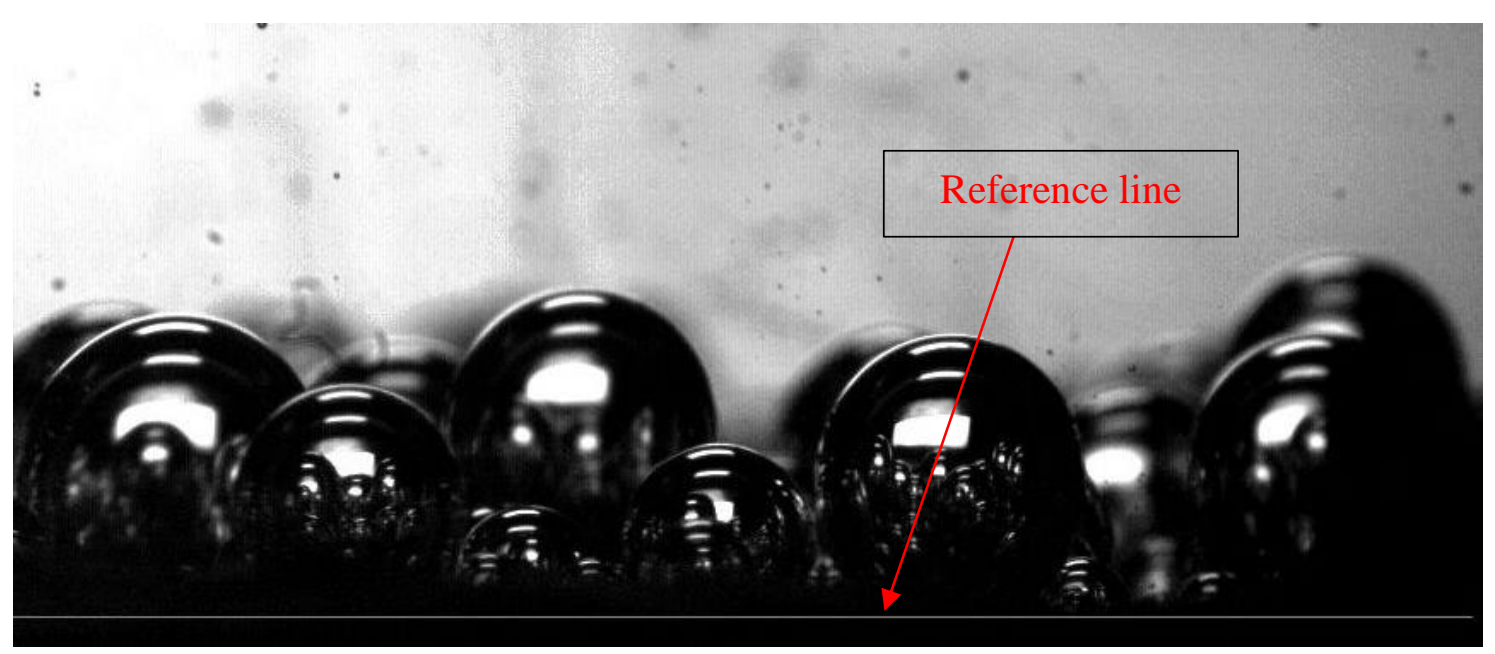

Fig. 2. Steady-state bubbles formed on heated brass surface (line width 1 pix).

At higher input power the bubbles get bigger and appears more bubbles on the heated surface when first bubbles start to detach from heat surface. By analysing the photos extracted from high speed videos, we determined the time of bubble growth, $t_{\mathrm{g}}$ (period of full bubble cycle, from forming on the surface to the departure), the bubble base diameter, $D_{\text {base}}$, contact angle in terms of growth time, the bubble release frequency and the departure diameter, $D_{\text {d. }}$ We noticed that there is no waiting time, $t_{\mathrm{w}}$ (period between the departure of bubble and appearance of the next bubble in the same position), so the frequency is estimated as $f \approx 1 / t_{g}$. The equivalent bubble departure diameter is calculated as the diameter of the sphere as:

$$
D_{d}=\sqrt[3]{x^{2} y}
$$

where $x$ is measured horizontal bubble dimension and $y$ is measured vertical bubble dimension.

A typical vapour bubble growing on the heated surface at surface superheat of $6 \mathrm{~K}$ is shown in Fig. 3.

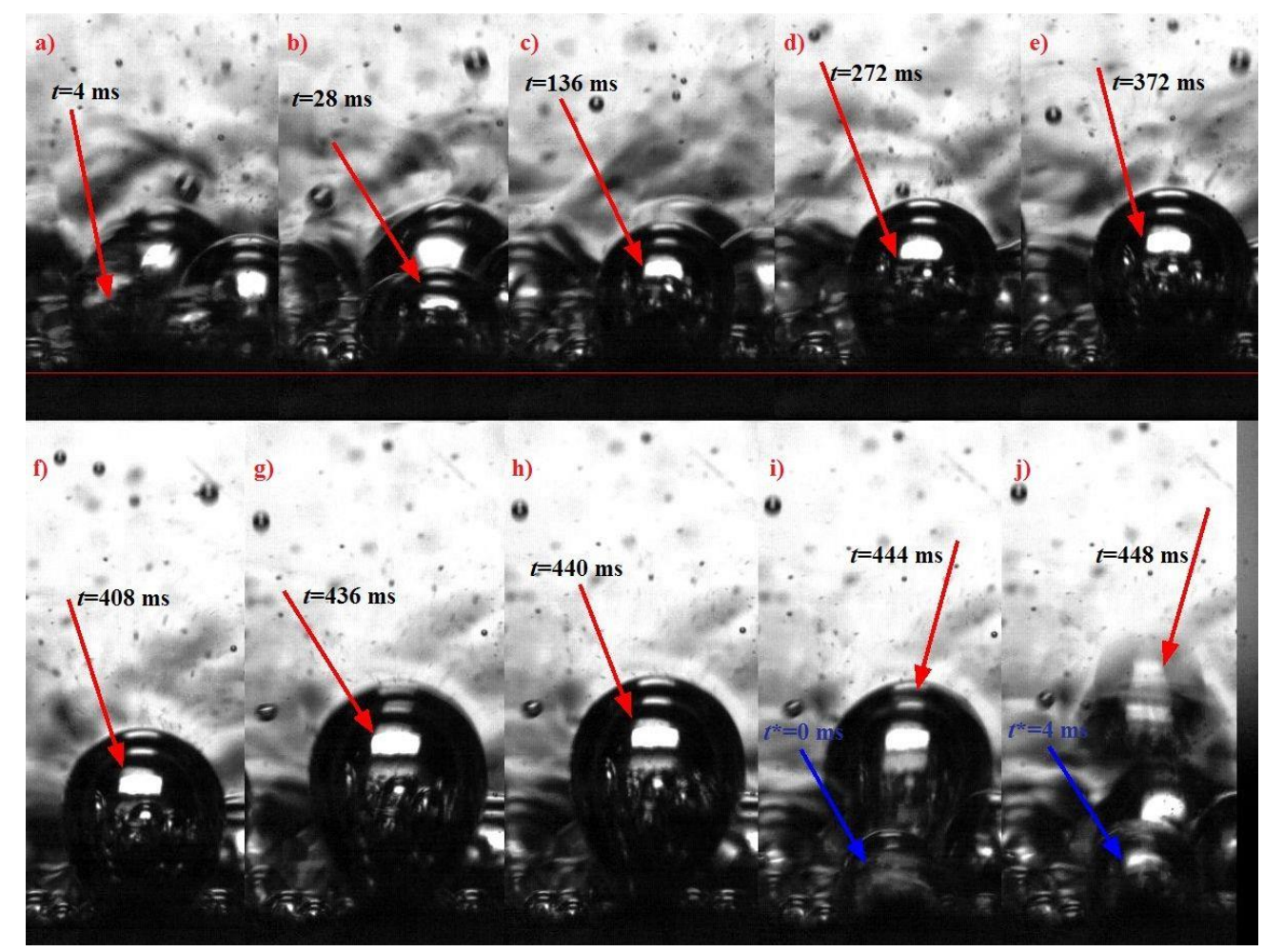

Fig. 3. Growth and departure of two consecutive vapour bubbles at surface superheat of $\Delta T_{\text {sat }}=6 \mathrm{~K}$, for brass surface, where $t$ is time from forming on surface. 


\subsection{Vapour bubble growth curves}

The Fig. 4 shows the bubble growth behaviour in terms of time evolution of the bubble base diameter at surface superheat of $\Delta T_{\text {sat }}=6 \mathrm{~K}$, rather than the variation in bubbles volume with time only.

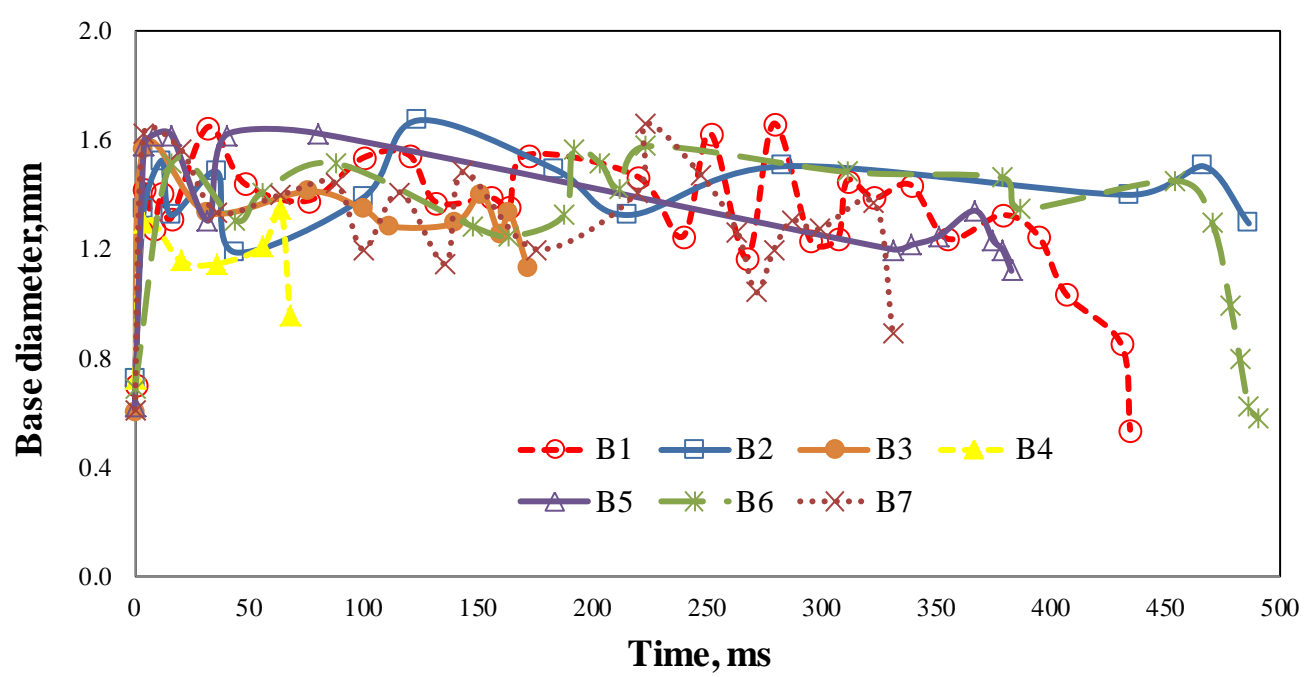

Fig. 4. Time evolution of bubble base diameter at surface superheat of $\Delta T_{\mathrm{sat}}=6 \mathrm{~K}$, for brass surface, B1-B7different position of bubble formation.

As it can be observed in Fig. 4, the base bubbles are observed to increases and decreases several times on the surface before departing. Generally, the maximum size of the bubble base diameter is reached in a relatively short period of the initial expanding time (less than $10 \mathrm{~ms}$ ). After that, the size of the base diameter is decreasing slowly in long period of time before reaching its minimum. In this period of time, the base diameter oscillated several times in its size. This oscillatory behaviour of the bubbles is possibly caused by condensation over a bubble cup as it grows beyond the superheated layer into the colder bulk liquid. Also, the bubbles appear to be relatively isolated from neighbouring sites during much of the growth period and grow to a relatively large size before detaching. In case of B3 and B4, the growth bubbles detach faster from the surface possibly because of randomly surface roughness. Same trend is observed for both test surfaces (copper and brass surface); for copper surface this case occurred on wall superheat of $5.5 \mathrm{~K}$.

The values of the base diameter and apparent bubble contact angles (Fig. 4 and Fig. 5) are averaged values obtained from seven different positions of bubble formation (B1-B7) with minimum of the five consecutive bubbles analysed. The time evolution of the apparent bubble contact angles for the low surface temperature case is shown in Fig. 5.

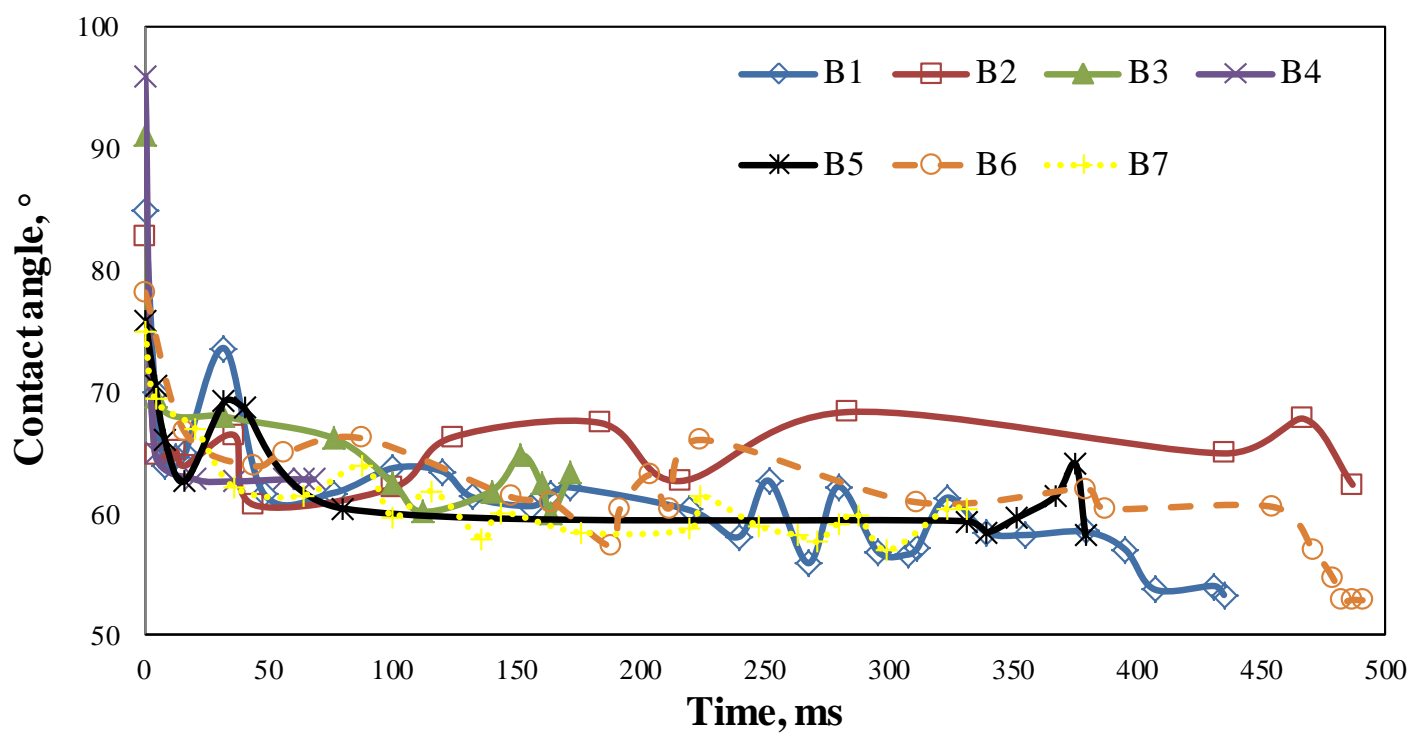

Fig. 5. Time evolution of the apparent bubble contact angles for the low surface superheat $\left(\Delta T_{\mathrm{sat}}=6 \mathrm{~K}\right), \mathrm{B} 1-\mathrm{B} 7-$ different position of bubble formation. 
The averaged values of apparent contact angles in the initial growing stage (right after formation of the bubble on the surface) are the highest which corresponds to the contact angle in initial bubble expanding time (for brass the averaged value is $\left.82^{\circ}\right)$. After a relatively short time $(t \approx 15 \mathrm{~ms})$ the values of contact angle are decreased and remain a relatively constant during the bubble growth process and relatively small oscillations (corresponds to the equilibrium contact angle; for brass: $\theta_{\mathrm{o}}=63^{\circ}$ ). Before the detachment, the values of the contact bubble angle are the lowest and correspond to the departure contact angle (for brass the averaged value is $59^{\circ}$ ). At surface superheat of $8 \mathrm{~K}$ and $10 \mathrm{~K}$, the bubble growth time is significantly decreased with only few oscillations observed in size of the base diameter for 8 $\mathrm{K}$ of superheat, as Fig. 6 shows.

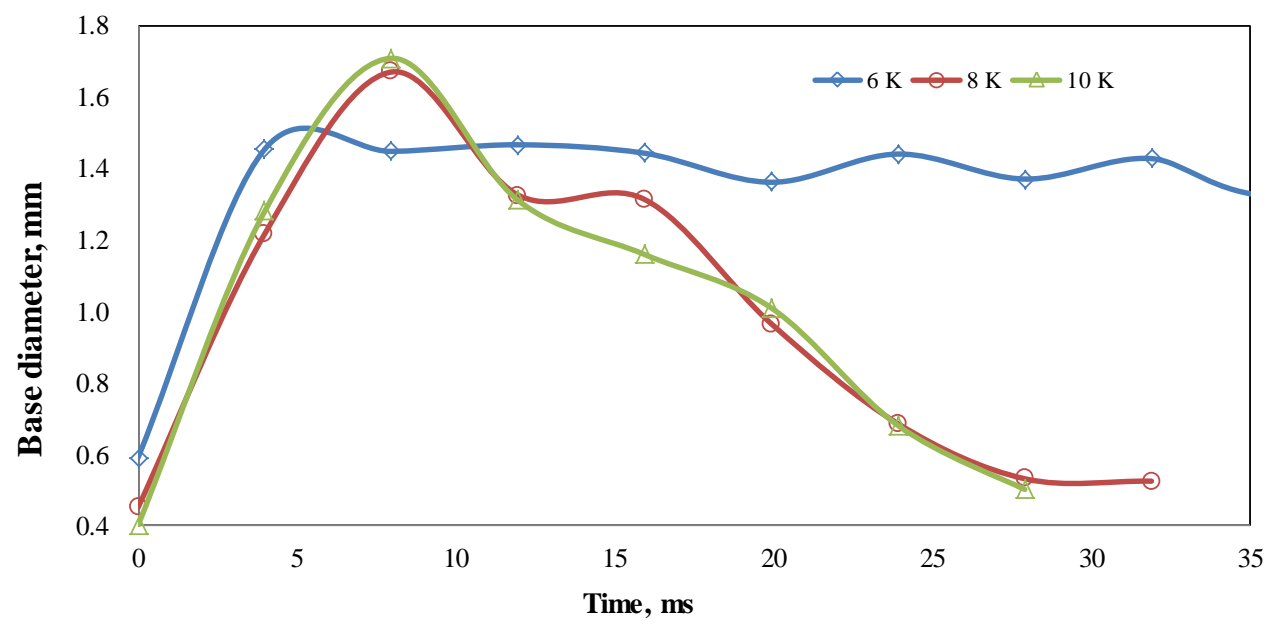

Fig. 6. Time evolution of the base diameter for brass surface in terms of different surface superheat.

With the waiting time between two consecutive bubbles of $0 \mathrm{~ms}$ (the time between departure of the previous bubble and when the new small bubble is visible on the extracted frame for the first time) a new bubble nucleates in the same position. An increase in size of the base diameter is observed in period of time of $8 \mathrm{~ms}$, reaching its maximum value. After that time, the decreasing trend of the base diameter is observed until departure time of $32 \mathrm{~ms}$ for $8 \mathrm{~K}$ of surface superheat and $27 \mathrm{~ms}$ for $10 \mathrm{~K}$ of surface superheat. In case for $8 \mathrm{~K}$ of superheat, a few oscillations in size of base diameter are observed in some cases. The maximum size of the base diameter increases with increase of the surface superheat, as shown in Fig. 6.

For $10 \mathrm{~K}$ of surface superheat formation of many small bubbles between initially activated nucleation sites are observed. For the brass test surface, the new activated positions appear in the centre and its vicinity (those locations are near initially observed position of bubble formation at B1, B4 and B3). The bubbles formed in positions B1, B4 and B3 tends to coalescence with those new small formed bubbles in direction of the centre of the test surface. As a consequence of this, we observed an increase in the size of the bubble base diameter and growth time. In the case of bubble forming positions of B1 and B4 the coalescence is appeared more than one time in single bubble cycle, as illustrated in Fig.7 and Fig.8.

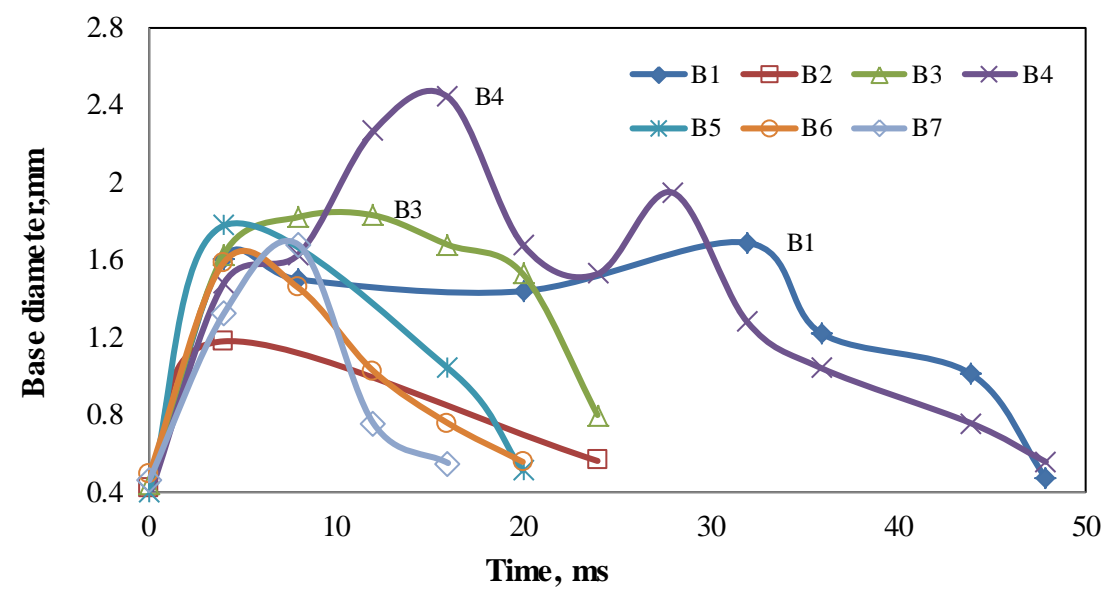

Fig. 7. Time evolutions of the base diameter for $10 \mathrm{~K}$ of surface superheat (initially activated positions B1, B3 and B4 that interacts with newly activated positions of bubble formation). 


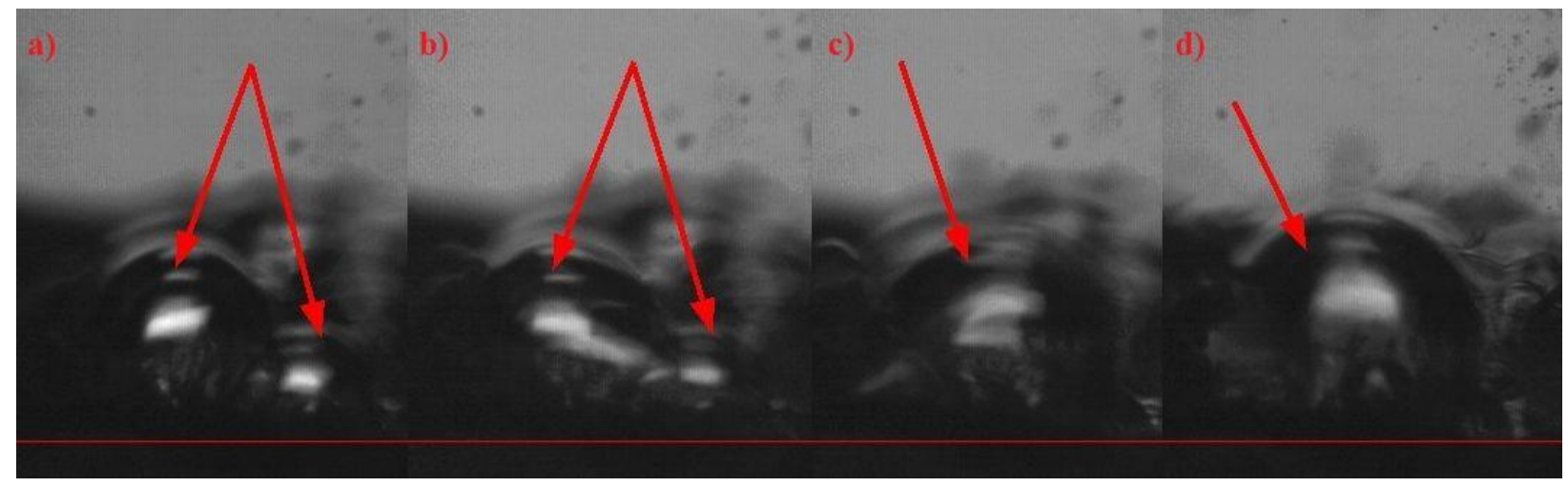

Fig. 8. Coalescence of two neighbouring bubbles on brass surface for $10 \mathrm{~K}$ of surface superheat (initially activated positions B4).

For the same temperature conditions, in the case of copper test surface, the small bubbles rarely coalescence with bubbles formed on initially activated positions. Instead of that, they stay relatively isolated from neighbouring bubbles with relatively short growth time, less than $8 \mathrm{~ms}$ (fast departing bubbles), as shown in Fig. 8. For those small bubbles it is difficult to determine bubble growing parameters, such as base diameter or departing contact angle.

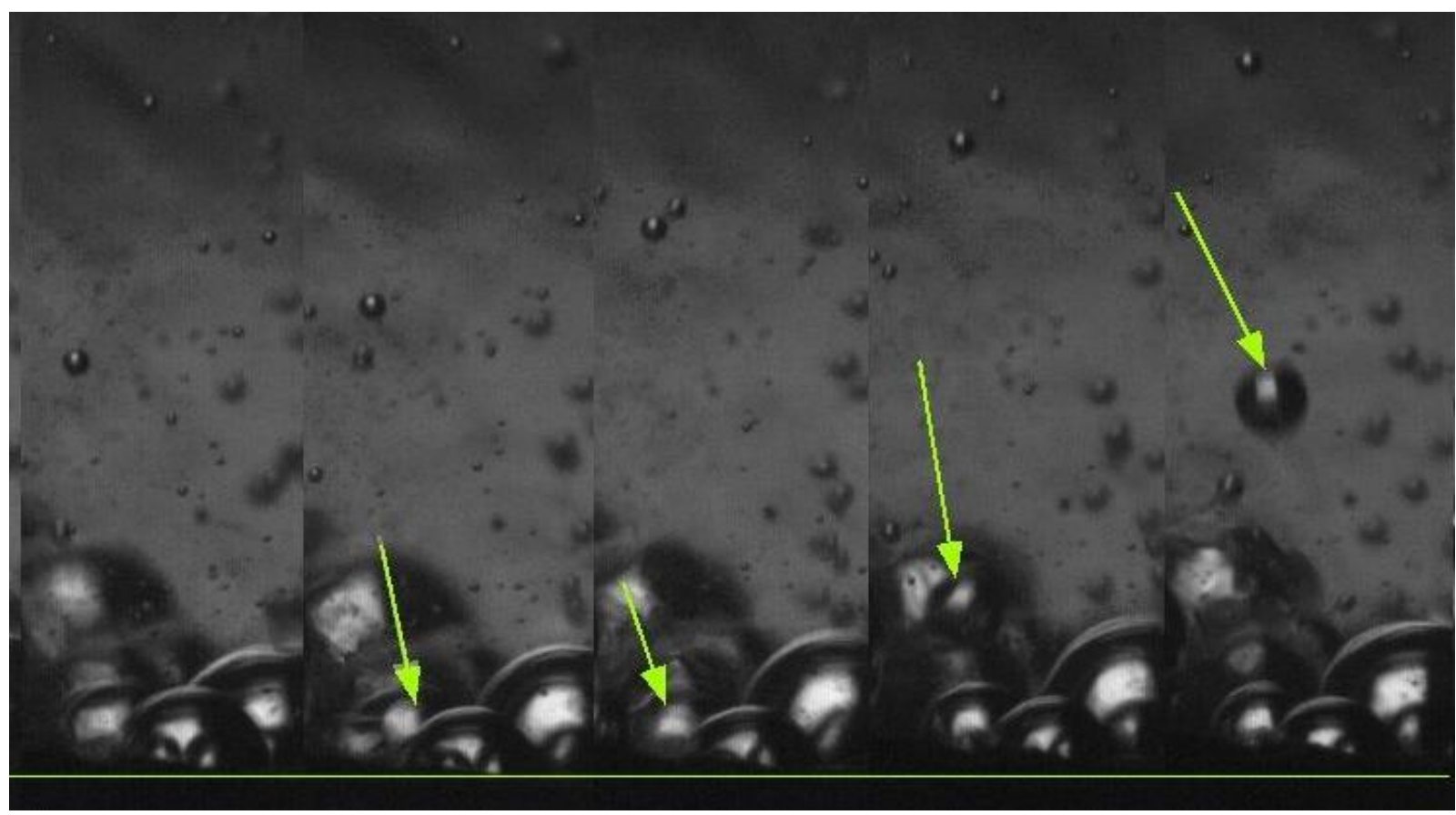

Fig. 9. Departing from copper surface for $10 \mathrm{~K}$ of surface superheat.

For the superheat of $10 \mathrm{~K}$, the size of the bubble base diameter is less than that for superheat of $8 \mathrm{~K}$ and $6 \mathrm{~K}$. The departure diameter and departure contact angle for both surfaces decrease with an increase of the surface superheat. The bubble departure frequency increases as the superheat increase, which is in agreement with data presented in published papers $[5,6]$. Based on the one values of sub-cooling we cannot make a general conclusion about the trend of the departure frequency in terms of the sub-cooling. Henry and Kim [7] found that increased sub-cooling reduce the departure frequency of the bubble in high gravity $(1.6 \mathrm{~g}-1.7 \mathrm{~g})$ boiling conditions and prolongs the time needed for the bubble to reach the departure size.

\subsection{Equivalent departure diameter}

The Fig. 10 shows comparison of the experimental data for equivalent bubble departure diameter with values calculated using correlations of other authors. In correlations of Fritz [2] and Phan et al. [4] we incorporated experimental departure contact angle in function of surface superheat (for brass: 59, 57 and 54 degrees with respect to surface superheat of 6,8 and $10 \mathrm{~K}$ and for copper: 51, 49, 44 and 43 degrees with respect to surface superheat of 5.5, $6,8$ and $10 \mathrm{~K})$. 

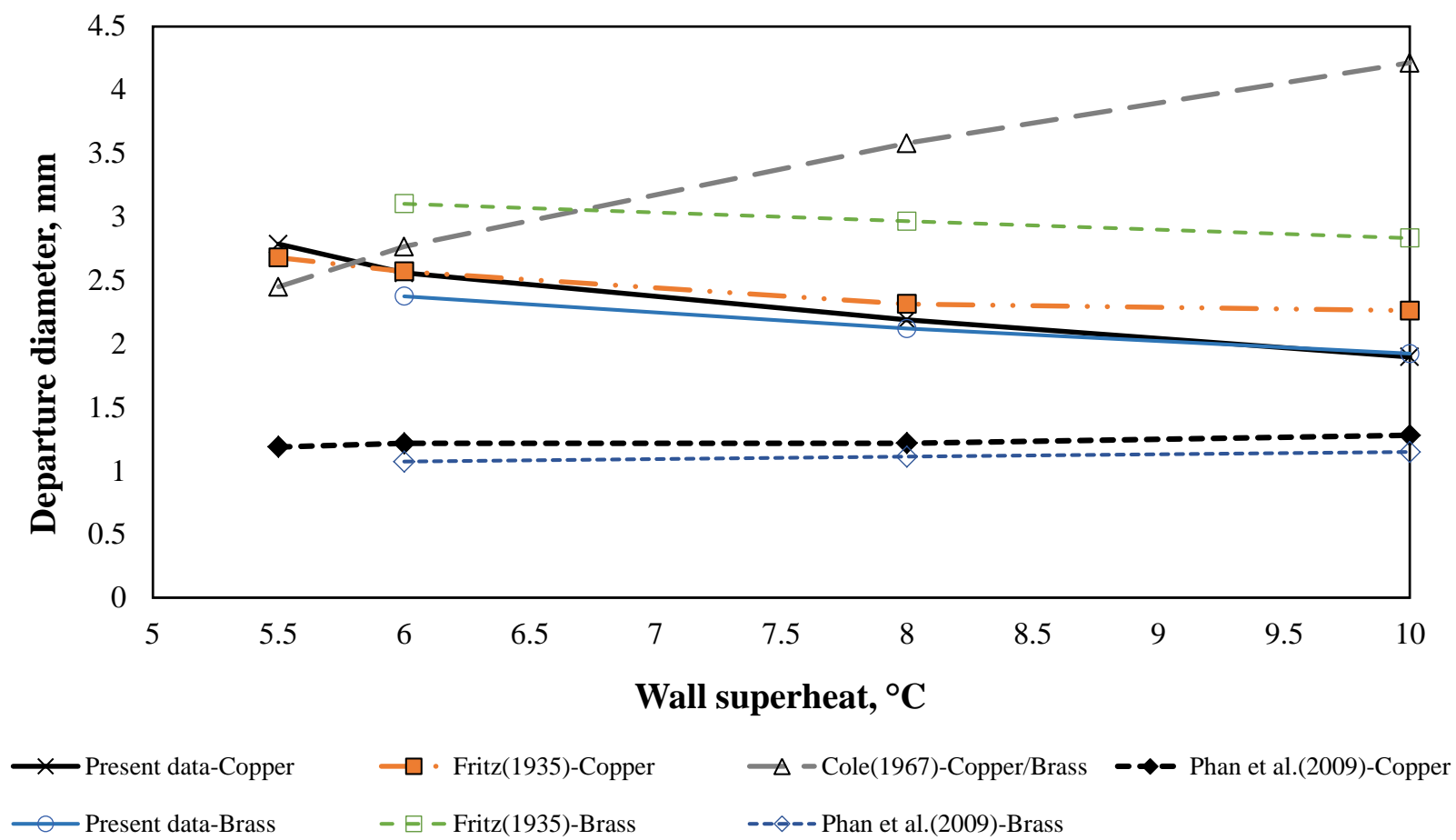

Fig. 10. Comparison of the experimental data for the equivalent bubble departure diameter with prediction from selected correlations in literature based on measured departure contact angles.

The experimental equivalent departure diameter is well predicted by the correlation of Fritz [2] for copper surface based on measured departure contact angles in function of the surface superheat. On the other hand, for the brass surface the predicted vales are overestimated. It is also important to note that the Fritz [2] model considers that the bubble departure diameter increases with increase of the contact angle which is not in agreement with data reported in the literature, $[4,5,8]$. The predicted departure diameter for brass is greater than that for copper surface for the same degree of superheat. However, the opposite trend is observed in the experimental data and with the model of Phanet al. [4]. The model of Phanet al. [4] underestimates the values of the experimental departure diameter for bubbles formed on initially activated nucleation positions, but this model does not take into account the effects of surface superheat.

Model of Cole [3] based on surface superheat and capillary length correlates the experimental results well only for the surface superheat of $6 \mathrm{~K}$ but for higher superheat the model overestimates the bubble departure diameter. This model predicts increasing trend for values of departure diameter with increase of superheat which is in agreement with data presented in literature. The contact angle is not considered in Cole model [3]. Demiray and Kim [6] pointed out that the bubbles are significantly smaller in high sub-cooling case than those in low sub-cooling case because the thinner superheated liquid layer slows down the bubble growth rate since the microlayer trapped between the bubble and surface is also reduced. They, also, indicated that the increased condensation at the top of the bubble limits the bubble size.

\section{Conclusions}

Vapour bubble formation, growth coalescence and subsequent departure from the heated surface in terms of the degree of the surface superheating and the liquid sub-cooling are presented in this paper. Available data from the literature usually refers to a saturated boiling. Thus, there are insufficient data in the literature for sub-cooled pool boiling.

For three surface superheat $\left(6^{\circ}, 8^{\circ}, 10^{\circ}\right)$, the time of bubble growth, the bubble base diameter, contact angle in terms of growth time, the bubble release frequency and the departure diameter are presented. Experimental values of contact angle just before its detachement were used in the calculation to be compared to experimental data. Tested correlations do not provide a good estimate of the bubble diameter as it detaches from the surfaces.

This can be due to influence of various parameters (bulk sub-cooling, surface superheat, contact angle, surface roughness, bubble growth period, surface thermo-physical characteristics, etc.). In the in existing correlations just some of them are considered. The growth rate of the bubbles, the departure frequency and departure diameters of the bubbles in terms of the degree of sub-cooling water will be investigated in more details and correlated in the following investigation. 


\section{References}

[1] Mohanty, R.L. and Das, M.K. (2017). A critical review on bubble dynamics parameters influencing boiling heat transfer, Renewable and Sustainable Energy Reviews, 78:466-494

[2] Fritz, W. (1935). Maximum volume of vapour bubbles. Phis. Z., 36: 379-384

[3] Cole, R. (1967). Bubble frequencies and departure volumes at subatmospheric pressures. Advances in Chemical Engineering Journal, 13: 779-783

[4] Phan, H.T.; Caney, N.; Marty, P.; Colasson, S. and Gavillet J. (2009). Surface wettability control by nanocoating: The effects on pool boiling heat transfer and nucleation mechanism. Int. J. of Heat and Mass Transfer, 52:54595471

[5] McHale, J.P., Garimella, S.V. (2010). Bubble nucleation characteristics in pool boiling of a wetting liquid on smooth and rough surfaces. Int. J. of Multiphase Flow, 36: 249-260

[6] Demiray, F. and Kim, J. (2004). Microscale heat transfer measurements during pool boiling of FC-72: effect of subcooling. Int. J. of Heat and Mass Transfer, 47:3257-3268

[7] Henry, C.D. and Kim, J. (2004). A study of the effects of heater size, subcooling and gravity level on pool boiling heat transfer. Int. J. of Heat and Fluid Flow, 25:262-273

[8] Teodori, E., Moita, A.S., Moreira, A.L.N. (2015). Influence of surface topography in the boiling mechanisms. Int. J. of Heat and Fluid Flow, 52:50-63. 